\title{
O GERENCIAMENTO DAS PARTES INTERESSADAS NO CONTEXTO PÚBLICO- PRIVADO DE UMA UNIVERSIDADE
}

Maria Leticia Santos Scholz ${ }^{1}$

Fernando Kaname Westphal ${ }^{2}$

Valdete De Oliveira Mrtvi ${ }^{2}$

\footnotetext{
${ }^{1}$ Universidade Federal do Paraná (UFPR) - Setor de Ciências Sociais Aplicadas

${ }^{2}$ Universidade Estadual de Londrina (UEL) - Centro de Estudos Sociais Aplicados
} 


\section{O GERENCIAMENTO DAS PARTES INTERESSADAS NO CONTEXTO PÚBLICO-PRIVADO DE UMA UNIVERSIDADE}

Resumo: Este artigo tem como objetivo levantar e descrever o relacionamento entre diversas partes interessadas (stakeholders) do Projeto Feira de Estágios Crescer, projeto de extensão universitária realizado anualmente por uma empresa júnior no Paraná e envolve o curso de graduação, representantes da universidade e iniciativa privada. A metodologia utilizada foi o estudo de caso único, com entrevistas aplicadas pessoalmente e telefone com sete grupos de stakeholders. Um grupo de discussão foi utilizado para levantar os stakeholders e discutir forças, fraquezas e possíveis impactos de cada. Foram identificados os stakeholders diretos e indiretos do projeto e caracterizados seus posicionamentos, necessidades e expectativas. Os resultados demonstraram que este gerenciamento envolve processos que, se realizados adequadamente, permite melhores resultados para o projeto e atendimento apropriado aos stakeholders. Observou-se também que o suporte de alguns stakeholders poderia sinergicamente atender demandas de outros, sugerindo a necessidade de maior interação e comunicação entre os stakeholders do projeto.

Palavras-chave: Projeto. Partes interessadas. Gerenciamento de partes interessadas. Stakeholders.

\section{Introdução}

Em cada empreendimento, projeto ou organização há pessoas e organizações com diversos interesses sobre as atividades e os resultados da ação em questão. Para Cabanis-Brewin e Dinsmore (2009), o sucesso de um projeto requer tratamento de problemas inesperados, de tal forma que o projeto seja executado e a satisfação das partes interessadas seja alcançada. Para Dinsmore e Cavalieri (2005), devem ser considerados quais métodos e tecnologias serão adequados para fornecer as informações necessárias para os interessados, assegurando que os recursos não sejam desperdiçados com informações ou tecnologias inadequadas.

Heldman (2009) considera que partes interessadas são as pessoas ou organizações que tem algum direito adquirido sobre seu projeto, que estão ativamente envolvidas com o trabalho do mesmo ou tem algo a ganhar ou perder como resultado do projeto. É preciso então identificar os objetivos e expectativas de cada uma das partes interessadas, para que sejam levados em conta e possivelmente essa identificação interfira no planejamento do projeto a seu favor, considerando suas necessidades e preocupações sobre o projeto.

Uma das características dos projetos no contexto público é que além dos clientes, tais projetos precisam atender às necessidades de diversos stakeholders (Fryer et al.2007). Nesse sentido, projetos realizados no âmbito de uma universidade pública configuram-se em um contexto importante para o estudo da gestão de stakeholders. Em particular, o projeto em estudo, o evento Feira de Estágios Crescer, executado por uma empresa júnior do curso de Administração, teve como propósito aproximar o setor privado, micro, pequenas e médias empresas (entre eles potenciais empregadores) e a universidade pública. Conforme Clemente, Marx e Carvalho (2017), potenciais aproximações entre setor público e iniciativa privada (tais como PPP, parcerias público-privadas) ampliam o leque de temas em gestão de projetos que podem ser explorados. 
O projeto contou com 16 estandes de várias empresas, que expuseram informações sobre si mesmas e promoveram cadastros para processos seletivos e estágios. Estimou-se a visitação de mais de mil pessoas, entre estudantes e profissionais, durante os três dias de evento. A empresa júnior organizadora possui 23 membros, sua governança se dá por uma diretoria executiva e seus membros são alunos do cursos de Administração operando em uma estrutura organizacional por projetos. As empresas juniores se inserem em um contexto universitário cujos membros contam com suporte de professores e estabelecem relações institucionais com representantes do colegiado do curso, departamento e outras instâncias da universidade. Além disso, afim de proporcionar o desenvolvimento de seus membros e dos alunos do curso de graduação em geral, promovem cursos, eventos e realizam projetos de consultoria à empresários interessados em obter suporte, estendendo as relações institucionais de forma a incluir a iniciativa privada.

Esta pesquisa aborda a gestão de stakeholders em projetos e mostra a importância do gerenciamento dos stakeholders; além de esclarecer sobre o conhecimento de suas expectativas, necessidades e posicionamentos. O problema de pesquisa foi delimitado da seguinte forma: Como o entendimento das expectativas, necessidades, a oferta de suporte e as estratégias das diversas partes interessadas podem contribuir para o sucesso do projeto?

Para Dinsmore e Cavalieri (2005, p178), "a definição de projeto de sucesso é: aquele que atinge ou excede as expectativas dos interessados". Heldman (2009) aborda que um aspecto fundamental do gerenciamento de projetos é conhecer as partes interessadas e os papeis que desempenham. Tais constituintes poder ser pessoas físicas ou jurídicas e que contam com a capacidade de influenciar positiva ou negativamente o projeto. Essa identificação deve ocorrer o mais cedo possível no projeto e prosseguir pelo seu ciclo de vida, pois a análise e estratégias das partes interessadas também devem ser revisadas e atualizadas conforme necessário.

Assim, os seguintes objetivos específicos foram definidos: a) identificar e categorizar os stakeholders envolvidos no projeto; b) identificar e descrever as contribuições efetivas e potenciais de cada parte interessada considerando o suporte ao projeto; c) analisar a missão das organizações envolvidas e os requisitos na perspectiva dos stakeholders; d) identificar a percepção geral acerca do projeto verificando, entre outros aspectos, os pontos de melhoria. $\mathrm{O}$ levantamento de partes interessadas é uma prática realizada na abertura de projetos, segundo o PMI (2017); sua análise aprofundada e o gerenciamento periódico das partes interessadas constituem-se como uma lacuna de pesquisa e escassez de modelos para realizar a gestão. O tema é uma preocupação em nível organizacional, cuja prática visa otimizar e agregar ao máximo os recursos dos parceiros do projeto. $\mathrm{O}$ modelo utilizado neste artigo pode ser replicado em outros projetos, visando maior satisfação das partes e sucesso no projeto como um todo.

\section{Referencial Teórico}

Segundo Dinsmore e Cavalieri (2005), um projeto é um empreendimento único, com início e fim determinados, que utiliza recursos e é conduzido por pessoas, visando atingir objetivos predefinidos. O projeto se caracteriza por ser temporário, mas, de acordo com o PMI (2017), suas entregas podem existir depois do encerramento do projeto. São realizados para cumprir objetivos através da produção de entregas, que podem ser de natureza social, econômica, material ou ambiental. Maximiano (1997) expõe que a complexidade de um projeto ou situação é medida de acordo com as variáveis que estão envolvidas, tais como 
multidisciplinaridade, número de pessoas, instalações usadas, duração, serviços ou organizações que precisam se mobilizar, etc. Outra característica dos projetos é a incerteza, que abordada por Maximiano (1997), muitos projetos partem de um problema no presente para desenvolver uma solução desconhecida no futuro; quanto maior o grau de desconhecimento, maior o grau de incerteza e risco.

O projeto também se caracteriza por ser exclusivo, que Dinsmore e Cavalieri (2005) expõem que todo produto ou serviço gerado por um projeto é diferente de outros produtos e serviços. Os projetos envolvem a realização de alguma coisa que jamais tenha sido realizada anteriormente e, portanto, é única. Para Heldman (2009), projetos existem para viabilizar um produto, serviço ou resultado que não existia antes. Isso pode incluir produtos tangíveis, serviços como consultoria ou gerência de projetos e funções de negócios que apoiam a empresa. 'Os projetos também podem produzir resultados, como um documento que detalha as descobertas de uma pesquisa" (HELDMAN, 2009 p.3). Para o Gerenciamento de Projetos Guia do Profissional (2006), o gerenciamento de projetos é a realização de um projeto e sua missão é alcançada por três elementos básicos: habilidades técnicas, interpessoais e administrativas.

No gerenciamento de projetos, a necessidade da criação de processos se deu para atender as demandas de maneira eficaz, em um ambiente caracterizado pela velocidade das mudanças e tornou indispensável um modelo baseado no foco em prioridades e objetivos (VARGAS, 2005, p.3). Além de processos, o gerenciamento de projetos para Vargas (2005) é um conjunto de ferramentas gerenciais, que permitem que a empresa desenvolva um conjunto de habilidades, destinadas ao controle de eventos não repetitivos, únicos e complexos, dentro de um cenário de tempo, custo e qualidade predeterminados. O PMI (2017) engloba processos consistentes para o gerenciamento de projetos e descreve algumas práticas para se aceitar, planejar, executar, controlar e encerrar um projeto. $\mathrm{Na} 4^{\mathrm{a}}$ edição do PMI (2008), haviam 44 processos e 49 na $6^{a}$ edição do PMI (2017). Os processos se dividem em áreas do conhecimento em projetos, que consistem em 9 áreas, a saber: integração, escopo, cronograma, custos, qualidade, recursos, comunicações, riscos, aquisições e gerenciamento das partes interessadas. Esta última área de conhecimento - stakeholders - não havia nas edições anteriores.

Dentro destas áreas, identificou-se a importância dos stakeholders. O tema é abordado principalmente quanto ao escopo do projeto, o qual define os objetivos principais e metas a serem cumpridas; também na área de comunicações, que tem como intuito proporcionar informação e comunicação entre as partes interessadas do projeto, após o levantamento, identificação e agrupamento das mesmas para diferentes estratégias de alcançá-las com efetividade. Chaves et al (2013) alega que o gerenciamento de projetos estava focado antes apenas no desenvolvimento e controle do escopo, cronograma e orçamento; hoje o que se vê é a necessidade adicional de garantir o engajamento dos stakeholders para o sucesso do mesmo.

De acordo com o PMI (2017), stakeholders no projeto são todas as pessoas, grupos ou organizações que podem impactar ou serem impactados pelo projeto. Segundo Patton (1998), o termo stakeholder apareceu na década de $60 \mathrm{em}$ uma consultoria prestada pelo Stanford Research Institute, para se referir à pessoas e organizações que não eram acionistas, mas que, sem seu suporte, a empresa poderia deixar de operar ou existir. Os interessados podem pertencer a diversas esferas como política, econômica, social ou tecnológica, e podem ser tanto internos à organização do projeto ou externos (Cleland e Ireland, 2007). 
Churchill e Peter (2000) tem uma abordagem que caracteriza de uma forma mais ampla o conceito. Para eles, stakeholders são indivíduos e grupos que também têm um interesse nas consequências das decisões das organizações e podem influenciá-las. Vê-se que existe uma relação de dependência entre estes grupos, formal ou informal. Além disso, Bethlem (1997) complementa focando os stakeholders diretos, ao dizer que o stakeholder é alguém que arrisca parte ou todo um valor ou bem de sua propriedade, apostando no resultado da atuação de uma empresa, e que ao fazer esta aposta vai provocar reflexos nos resultados da empresa.

"Todas essas pessoas têm um interesse, o que significa que elas têm uma expectativa própria em relação ao projeto" (YOUNG, 2008, p119). É preciso considerar estas expectativas e aquelas exigências do projeto; o nível de interesse de cada um é suficiente para justificar o fato de que devem ter espaço para darem opiniões e que o projeto deve escutá-las. A falta dessa etapa, como Young (2008) aborda, mostra que pode levar a conflitos, perturbações e interferências posteriores. Alves Filho (2001) considera ser necessário um modelo para gestão de stakeholders para se ajustar às exigências dos tempos atuais e à um novo modo de gerir as organizações, já que somente a visão dos acionistas não basta para o progresso das empresas face à gama de atores que exercem influência na organização. Para Freeman (1984), para gerenciar os stakeholders, a organização deveria responder à três perguntas básicas: Quem são os stakeholders? O que eles querem (em relação aos seus objetivos e metas)? De quem forma eles atingirão seus objetivos e metas? Vê-se a necessidade de compreender quem são para entender a relação de interesses e necessidades de cada um.

O envolvimento dos stakeholders pode determinar o (in)sucesso do projeto; Cleland e Ireland (2007, p2) consideram: "(...) um projeto que ultrapassou os objetivos de custo e de prazo mas proporciona os resultados esperados pode ser considerado um sucesso pelo usuário; um membro da equipe que adquire uma experiência valiosa pode considerar que o projeto foi um sucesso;" e diversas são as perspectivas de um mesmo fenômeno para serem geridas.

Cabanis-Brewin e Dinsmore (2009) traduzem que o papel das partes interessadas nem sempre é tão facilmente compreendido. É preciso saber as exigências e interesses das partes interessadas e desenvolver estratégias para tratar os diferentes níveis de poder das partes interessadas. Para os mesmos autores, as metas de sucesso do projeto devem incluir as necessidades e desejos das partes interessadas no projeto. Para isso é necessária a comunicação e abertura por diversos meios, como propagandas, pesquisa de opiniões, reuniões públicas ou ainda linhas telefônicas destinadas à emergências. As metas de cada parte devem ser estabelecidas, e estas podem ser conflitantes ou complementares e ter impacto positivo ou negativo no projeto. Aponta-se que "frequentemente, as partes interessadas priorizam os aspectos qualitativos do projeto. Suas preocupações incluem saúde, segurança, confiabilidade, qualidade e questões ambientais" (CABANIS-BREWIN; DINSMORE 2009 p.183). É preciso elaborar uma forma de gerenciar de maneira sistemática as exigências e atividades do projeto, e lidar com cada uma das partes interessadas.

Valle et al (2010), fala acerca dos níveis de autoridade e de responsabilidade das partes interessadas, que podem se alterar durante a linha do tempo de um projeto; e isso varia a partir das contribuições e patrocínios durante o projeto. O autor argumenta que os stakeholders que ignoram essa responsabilidade podem acabar prejudicando os objetivos do projeto, da mesma forma que os gerentes de projeto não podem se esquecer ou ignorar as partes interessadas. É 
preciso um gerenciamento desses, que de acordo com Valle et al (2010), é dividida em duas partes: a identificação dos intervenientes e a análise.

\section{Modelos de Gerenciamento de Stakeholders}

Os cinco modelos a seguir são apresentados para identificação e gestão das partes interessadas. A partir dos expostos, o instrumento de pesquisa foi elaborado para abarcar todos os passos e temáticas pertinentes.

Heldman (2009) utiliza 3 passos para análise das partes interessadas em um projeto. $\mathrm{O}$ primeiro é identificar todas as potenciais partes interessadas e capturar informações relevantes, cuja saída é o registro das partes interessadas; o segundo é identificar o potencial impacto ou o suporte ao projeto que cada um poderia gerar e então classificá-los de acordo com o impacto, a fim de que se possam criar estratégias para lidar com eles caso ocorram; e o terceiro é avaliar a influência e os potenciais impactos negativos que as principais partes interessadas podem ter sobre o projeto;

Para o PMI (2017), são 4 processos a serem observados: identificar as partes interessadas para documentar informações relevantes sobre seus interesses; planejar o engajamento para desenvolver abordagens de envolvimento; gerenciar o engajamento para comunicar-se e atender suas necessidades e expectativas; e monitorar o engajamento das partes, através da modificação de planos e estratégias de engajamento.

Moura (2013), por sua vez, comenta que o processo de conhecimento das partes interessadas pode incluir a identificação das partes interessadas no projeto; a identificação de informação adicional relevante sobre as partes interessadas; a análise de suas necessidades, desejos, preocupações, papeis e níveis de conhecimento; e a classificação do posicionamento das partes interessadas de acordo com o seu poder, influência e suporte ao projeto. A análise das partes também podem ser categorizadas em autoridade versus interesse, relacionando a capacidade que elas terão de influenciar as decisões do projeto com o impacto que essas decisões tem em seus interesses, e também em autoridade versus atitude, relacionando o nível de autoridade das partes interessadas com o tipo de atitude perante o projeto.

Em um modelo elaborado por Cleland e Ireland (2007), há sete passos que devem ser seguidos em um processo de gerenciamento dos interessados no projeto. São eles: a identificação dos interessados; a coleta de informações sobre os interessados; a identificação da missão do interessado; a determinação dos pontos fortes e fracos dos interessados; a identificação da estratégia do interessado; levantamento da previsão do comportamento do interessado e a implementação de estratégia de gerenciamento de interessados.

Um quinto modelo aqui proposto, revelado por Valle et al (2010), a primeira parte, de identificação, pode ser feita em três etapas: a primeira atribui categorias aos intervenientes, a segunda a designação e a terceira quem são os que se encaixam nesta linha. Na segunda parte então, que é a análise, algumas ações são sugeridas para tal, como a análise do comprometimento necessário (necessidade de ações, crenças, buy-in, entendimento e conscientização); a análise do suporte do interveniente (contrato apoiador ou opositor, confiante ou não); o levantamento de prioridades do interveniente (foco em custo, prazo, qualidade do produto, interesses no projeto e critérios de sucesso); a verificação da previsão de comportamento (volatilidade, reação a eventos futuros, impacto potencial do comportamento futuro); a análise do poder do interveniente (posicional ou pessoal, forças, fraquezas, alianças, 
impacto nos objetivos do projeto) e a definição de influência do interveniente (se é tomador de decisão, facilitador ou formador de opinião).

Quadro 1 - Comparação dos modelos e etapas de gerenciamento de stakeholders

\begin{tabular}{|c|c|c|c|c|c|}
\hline Etapas & $\begin{array}{c}\text { Cleland e } \\
\text { Ireland }(\mathbf{2 0 0 7 )}\end{array}$ & Heldman (2009) & $\begin{array}{l}\text { Valle et al } \\
(2010)\end{array}$ & Moura (2013) & $\begin{array}{c}\text { PMI } \\
(2017)\end{array}$ \\
\hline 1 & $\begin{array}{l}\text { Identificação dos } \\
\text { interessados }\end{array}$ & $\begin{array}{c}\text { Identificar partes } \\
\text { interessadas, capturar } \\
\text { informações relevantes }\end{array}$ & $\begin{array}{l}\text { Análise do } \\
\text { comprometi } \\
\text { mento } \\
\text { necessário }\end{array}$ & $\begin{array}{l}\text { Identificação das } \\
\text { partes interessadas no } \\
\text { projeto }\end{array}$ & $\begin{array}{c}\text { Identificar } \\
\text { as partes } \\
\text { interessadas }\end{array}$ \\
\hline 2 & $\begin{array}{c}\text { Coleta de } \\
\text { informações }\end{array}$ & $\begin{array}{c}\text { Identificar potencialimpacto } \\
\text { ou suporte ao projeto, e } \\
\text { classificá-lo para criação de } \\
\text { diferentes estratégias }\end{array}$ & $\begin{array}{c}\text { Suporte do } \\
\text { interveniente }\end{array}$ & $\begin{array}{c}\text { Identificação de } \\
\text { informação adicional }\end{array}$ & $\begin{array}{c}\text { Planejar o } \\
\text { engajament } \\
\text { o }\end{array}$ \\
\hline 3 & $\begin{array}{l}\text { Identificação da } \\
\text { missão }\end{array}$ & $\begin{array}{l}\text { Avaliar a influência e os } \\
\text { principais impactos } \\
\text { negativos que podem ter } \\
\text { sobre o projeto }\end{array}$ & $\begin{array}{l}\text { Prioridades } \\
\text { do } \\
\text { interveniente }\end{array}$ & $\begin{array}{c}\text { Análise de } \\
\text { necessidades, desejos, } \\
\text { preocupações, papeis e } \\
\text { níveis de } \\
\text { conhecimento }\end{array}$ & $\begin{array}{c}\text { Gerenciar o } \\
\text { engajament } \\
\text { o }\end{array}$ \\
\hline 4 & $\begin{array}{c}\text { Determinação } \\
\text { dos pontos fortes } \\
\text { e fracos }\end{array}$ & & $\begin{array}{l}\text { Previsão de } \\
\text { comportamen } \\
\text { to } \\
\end{array}$ & $\begin{array}{c}\text { Posicionamento das } \\
\text { partes interessadas de } \\
\text { acordo como seu } \\
\text { poder, influência e } \\
\text { suporte ao projeto } \\
\end{array}$ & $\begin{array}{c}\text { Monitoraro } \\
\text { engajament } \\
\text { o }\end{array}$ \\
\hline 5 & $\begin{array}{c}\text { Identificação da } \\
\text { estratégia }\end{array}$ & & $\begin{array}{c}\text { Poder do } \\
\text { interveniente }\end{array}$ & & \\
\hline 6 & $\begin{array}{c}\text { Previsão do } \\
\text { comportamento } \\
\text { do interessado }\end{array}$ & & $\begin{array}{l}\text { Influência do } \\
\text { interveniente }\end{array}$ & & \\
\hline 7 & $\begin{array}{l}\text { Implementação } \\
\text { de estratégia de } \\
\text { gerenciamento } \\
\text { de interessados }\end{array}$ & & & & \\
\hline
\end{tabular}

Fonte: Os autores.

A partir dos passos principais descritos por cada autor nos modelos anteriores, o Quadro 1 resume os passos para identificação e gerenciamento de cada autor.

\section{METODOLOGIA}

Adotou-se a pesquisa qualitativa descritiva e o delineamento adotado foi o estudo de caso, pois, segundo Glessler (2004), sua grande vantagem é a elevação da validade interna. Para Fachin (2001), o estudo de caso se caracteriza por ser um estudo intensivo. É levada em consideração principalmente a compreensão, como um todo, no assunto investigado. Todos os aspectos são investigados e podem até aparecer relações que de outras formas não seriam descobertas. $\mathrm{O}$ presente estudo visa se aprofundar em relação à uma técnica adequada de análise de stakeholders por um projeto da empresa júnior em análise.

$\mathrm{Na}$ primeira fase da pesquisa, foi aplicado o método de grupo de discussão com os membros da equipe organizadora, a fim de fornecer informações necessárias para realização da segunda parte. $\mathrm{O}$ roteiro preparado para conduzir o grupo de discussão abordou a explicação 
do estudo, do conceito das partes interessadas e tópicos sobre forças, fraquezas e impactos para serem usados como direcionamento.

A coleta de dados primários foi realizada por meio de trabalho de campo, com aplicação de entrevista estruturada. $O$ instrumento foi elaborado a partir dos modelos apresentados na seção 2.3. O modelo de pesquisa de Cleland e Ireland (2007) foi a principal contribuição devido aos aspectos operacionais e objetivos. Também foi considerado o segundo passo proposto por Heldman (2009) para complementar os conceitos de Valle et al (2010), que é identificar o potencial impacto ou o suporte ao projeto que cada um poderia gerar. O conceito e a forma de registro proposto pelo PMI (2017) também foi utilizado, nas questões referentes às exigências e opinião. Foi utilizado o $3^{\circ}$ passo de Moura (2013), que se refere aos papéis, desejos e nível de conhecimento em relação ao projeto. O quadro 2 apresenta uma síntese das categorias de análise.

Quadro 2 - Categorias de análise

\begin{tabular}{|c|c|c|}
\hline Questão & Categorias de análise & Referência \\
\hline Gênero, idade, entidade, cargo e tempo no cargo & Perfil & Cleland e Ireland (2007) \\
\hline Qual foi o papel da instituição dentro do projeto? & Papel & Heldman (2013) \\
\hline Que tipo de suporte esta instituição pode dar ao projeto? \\
\hline $\begin{array}{c}\text { Qual o objetivo/estratégia da entidade ao participar do } \\
\text { projeto? }\end{array}$ & Objetivos/ es tratégia & Cleland e Ireland (2007) \\
\hline $\begin{array}{c}\text { Quais são os benefícios e vantagens que a instituição vê ao } \\
\text { participar do projeto? }\end{array}$ & Desejos e necessidades & Moura (2013) \\
\hline $\begin{array}{c}\text { Qual é a mis são da entidade e como o projeto pode impactar } \\
\text { nela? }\end{array}$ & Mis são & Cleland e Ireland (2007) \\
\hline $\begin{array}{c}\text { Quais são as exigências da entidade/o que é essencial para a } \\
\text { participação no projeto? }\end{array}$ & Exigências & PMI (2017) \\
\hline $\begin{array}{c}\text { Quais são os pos síveis benefícios e vantagens vistas ao } \\
\text { participar do projeto? }\end{array}$ & Desejos e necessidades & Moura (2013) \\
\hline Qual a sua opinião sobre a realização do projeto? & Opinião & PMI (2017) \\
\hline O que pode ser melhor num próximo projeto? & Prevĩo de \\
comportamento & Cleland e Ireland (2007) \\
\hline
\end{tabular}

Fonte: Os autores.

A coleta dos dados secundários, além da revisão bibliográfica, foi feita a partir da análise de documentos internos, como o termo de abertura do projeto das duas edições do evento realizadas - que continha as expectativas de cada membro da equipe organizadora e detalhes do projeto - e banco de dados dos membros da empresa júnior, a fim de levantar tempo de empresa e funções. Através deste documento foi possível realizar uma triangulação de informações para identificar partes interessadas que não teriam sido comentadas no grupo de discussão; ou ainda encontrar respostas contraditórias dos membros organizadores quanto às obtidas nas entrevistas individuais na segunda fase com os mesmos entrevistados.

$\mathrm{Na}$ segunda fase, à todas as partes interessadas identificadas no grupo de discussão foi enviado um $e$-mail solicitando a entrevista e apresentando o tema e objetivos do projeto. $\mathrm{O}$ questionário foi validado por outros membros da empresa júnior e docentes do curso em questão. Foram entrevistadas as seguintes partes interessadas do projeto: equipe organizadora, empresas expositoras, Universidade, empresa júnior, apoiadores de infraestrutura, apoiadores institucionais e patrocinadores. Destes sete grupos de stakeholders, foram realizadas 13 entrevistas no total. As entrevistas foram gravadas com autorização das partes para posterior 
transcrição das respostas obtidas. Foram agrupados os stakeholders segundo seus papeis dentro do Projeto, com uma breve descrição sobre quem são e o número de respondentes, como no quadro 3.

Quadro 3 - Definição dos sujeitos da pes quisa

\begin{tabular}{|c|c|c|}
\hline Stakeholder & Descrição & Sujeitos da Pesquisa / Total \\
\hline Empresas expositoras & Empresas que participaram com stands & $6 / 19$ \\
\hline Universidade & $\begin{array}{c}\text { Departamento do curso da empresa júnior, Colegiado } \\
\text { do Curso, Prefeitura do Campus e Centro de Educação } \\
\text { Física e Es porte (local do evento) }\end{array}$ & $3 / 4$ \\
\hline Entidade Organizadora & Membros da diretoria da empresa júnior organizadora & $2 / 2$ \\
\hline Equipe Organizadora & Membros da equipe organizadora & $4 / 4$ \\
\hline Apoio (Infraestrutura) & Empresa de móveis, stands e coffee-break & $1 / 3$ \\
\hline Apoio (institucional) & Núcleo de Empresas Juniores & $1 / 1$ \\
\hline Patrocinadores & $\begin{array}{c}\text { Empresas que patrocinaram financeiramente ou } \\
\text { materiais (parte gráfica) }\end{array}$ \\
\hline
\end{tabular}

Fonte: Os autores.

\section{RESULTADOS E DISCUSSÃO}

A empresa júnior estudada foi fundada na década de 90 . Se enquadra no conceito de empresa júnior, pois segundo o CNEJ (2014), é caracterizada pela união de alunos matriculados numa instituição de ensino superior, organizados em uma associação civil com o intuito de realizar projetos e serviços que contribuam para o desenvolvimento do país e de formar profissionais capacitados e comprometidos com este objetivo. A missão da entidade é desenvolver seus membros para prestarem serviços de qualidade, mostrando assim a necessidade de realizar projetos que contribuam pessoal e profissionalmente aos membros. $\mathrm{O}$ projeto escolhido foi a segunda edição realizada do evento, que consistiu na organização anual de uma feira cujo foco principal foi trazer empresas da região para exposição e contato com estudantes da Universidade. O objetivo do projeto da empresa júnior, descrito no termo de abertura, foi aproximar e incentivar o relacionamento entre estudantes, profissionais $\mathrm{e}$ empresas. Diante deste contexto, percebeu-se um cenário que envolvia diversas partes interessadas com diferentes expectativas e necessidades que precisavam ser atendidas.

No termo de abertura do projeto da $1^{a}$ Edição, o documento foi elaborado pela equipe anterior sem históricos ou precedentes; nesta ocasião, os membros registraram a identificação de apenas três partes interessadas, que foram a Entidade organizadora, as empresas expositoras e a Universidade como um todo. No termo de abertura da segunda edição - objeto desta pesquisa - o tópico que levanta e faz uma sucinta descrição da expectativa ou interesse de cada stakeholder não foi incluído. Utilizando a abordagem de Patton (1998) e trazendo à realidade do projeto, mostra que o evento não pode ter seu início sem um levantamento e análise sobre a influência de cada stakeholder, pois pode acarretar no fim, no encerramento do projeto quando em execução ou até mesmo impedir a ocorrência de uma próxima edição. Além disso, observouse que ao final do projeto em análise não foi realizada uma comparação entre as expectativas iniciais dos membros da equipe organizadora e após o fim do projeto.

Além da análise documental, o grupo de discussão ajudou a definir as partes interessadas do projeto. Segundo Campbell (1997), é difícil estabelecer ou definir quem é e quem não é um stakeholder. Para isso, é necessário conhecer os objetivos da organização e sua atuação no mercado, para identificar as forças que interagem de forma direta ou indireta. A 
partir do roteiro preparado, foram levantados e agrupados os seguintes stakeholders de acordo com suas funções: i) empresas expositoras: estiveram presentes no evento 19 empresas; ii) Universidade: foram identificados e agrupados aqui como universidade o departamento do curso da empresa júnior, o colegiado do curso, a prefeitura do Campus e o Centro de Educação física e esporte, onde foi realizado o evento; iii) a entidade organizadora, a empresa júnior; iv) a equipe organizadora, composta por um gerente de projetos e três consultores, divididos em áreas (infraestrutura, financeiro e comunicação); v) entidades ligadas à infraestrutura do evento, como locação de móveis, stands e fornecimento de coffee-break; vi) o núcleo de empresas juniores, pelo fato da empresa júnior estar associada ao núcleo; e vii) os patrocinadores financeiros, que contribuíram diretamente com recursos financeiros ou intermediaram contas do Projeto, se disponibilizando a pagar por custos específicos que o projeto teria. O perfil dos stakeholders pode ser observada no Quadro 4.

Quadro 4 - Perfil dos entre vistados das partes interessadas

\begin{tabular}{|c|c|c|c|c|c|}
\hline Entrevistado & Gênero & Idade & Entidade & Cargo & $\begin{array}{c}\text { Tempo } \\
\text { no cargo }\end{array}$ \\
\hline 1 & Feminino & 20 & Expositora & Es tagiária & 10 meses \\
\hline 2 & Feminino & 52 & Expositora & Assistente Administrativo & 2 anos \\
\hline 3 & Masculino & 51 & Expositora & Analista de Negócios & 5 meses \\
\hline 4 & Masculino & 31 & Expositora & Gerente & 5 anos \\
\hline 5 & Feminino & 24 & Expositora & Coordenadora de Eventos & 3 anos \\
\hline 6 & Feminino & 21 & Expositora & Es tagiária & 3 meses \\
\hline 7 & Feminino & 60 & Universidade & Docente & 18 anos \\
\hline 8 & Feminino & 33 & $\begin{array}{c}\text { Apoio } \\
\text { (infraestrutura) }\end{array}$ & Proprietária & 6 anos \\
\hline 9 & Feminino & 21 & $\begin{array}{c}\text { Apoio } \\
\text { (Institucional) }\end{array}$ & Presidente & 8 meses \\
\hline 10 & Feminino & 21 & Organizadora & $\begin{array}{c}\text { Coordenadora do Núcleo } \\
\text { Administrativo }\end{array}$ & 5 meses \\
\hline 11 & Feminino & 19 & Organizadora & Presidente & 5 meses \\
\hline 12 & Feminino & 53 & Universidade & Secretária Executiva & 35 anos \\
\hline 13 & Masculino & 53 & Universidade & Chefe da divisão do suporte técnico & 4 anos \\
\hline
\end{tabular}

Fonte: dados da pesquisa.

No grupo de discussão foram levantadas forças e fraquezas de cada stakeholder. No início do grupo, um membro contribuiu com apenas duas partes interessadas; enquanto os demais deram o dobro de exemplos cada um. Os próprios participantes concluíram que a diferença de informação poderia ser devido às funções específicas de cada um e ausência de compartilhamento regular. Além disso, apenas um participante citou durante o grupo opiniões, vantagens e aspectos referentes à Universidade (colegiado, departamento, prefeitura, e centro onde foi realizado). Esta situação sugere a necessidade de futuros estudos a respeito da comunicação dentro do projeto. Apenas a entidade organizadora foi vista como insubstituível enquanto os demais stakeholders poderiam ser alterados. As empresas expositoras foram destaque quanto aos pontos negativos: lentidão referente aos contratos e dificuldades de comunicação foram os principais tópicos.

Por meio do banco de dados dos membros da empresa júnior, observou-se que houve uma troca na equipe durante o projeto e não foram recolhidas as expectativas do novo membro e atualizado o termo de abertura. Para a análise dos papeis dos stakeholders, buscou-se verificar 
algumas informações já obtidas com a equipe organizadora por meio da triangulação de dados conforme discussão teórica sobre o papel de cada parte interessas proposto por Moura (2013). Suas respostas se dividiram entre papel de expositora, universidade-apoiador, apoioinfraestrutura, apoio-institucional, entidade organizadora, universidade-recursos e apoio, e universidade-manutenção e infraestrutura. Já em relação ao suporte que cada parte interessada poderia fornecer, realizou-se uma síntese dos resultados no Quadro 5.

Quadro 5 - Suporte fornecido ou que pode ria ofe recer em um próximo proje to

\begin{tabular}{|c|c|}
\hline Entrevistado & Suporte que pode/poderia fornecer \\
\hline 1 & Pessoas para trabalhar no local \\
\hline 2 & Pessoas para trabalhar no local e presença de uma empresa de consultoria em informática \\
\hline 3 & Ajuda na divulgação, mídias internas e sociais \\
\hline 4 & Apoio gráfico, divulgação \\
\hline 5 & Pessoas para trabalhar no local \\
\hline 6 & Apoio de bebidas \\
\hline 7 & Infraestrutura e apoio gráfico \\
\hline 8 & Locação de materiais e acessórios de escritório \\
\hline 9 & Staffs, apoio financeiro inicial, equipe do projeto, conhecimento de eventos anteriores \\
\hline 10 & RHerticipar para organização do evento por mídias, flyers, camisetas $\mathrm{e}$ \\
\hline 11 & Segurança, energia, móveis, painéis, tablado, logística, ajuda no layout do evento, parte gráfica \\
\hline 12 & Manutenção, espaço físico, banheiros e ves tiários \\
\hline 13 &
\end{tabular}

Fonte: dados da pesquisa.

Ao comparar com o conteúdo do grupo de discussão, percebeu-se que a entidade organizadora forneceu o suporte esperado pelos membros da equipe, ao falar que a "entidade organizadora ajudou e apoiou do início ao fim'. A análise do suporte fornecido (Quadro 5) revela a possibilidade de inclusão de novos stakeholders para projetos futuros, principalmente no que se refere aos prestadores de serviços complementares. Como exemplo, empresas expositoras dispostas a ajudar na divulgação do projeto, apoio com bebidas, apoio gráfico, seguranças, manutenção e de pessoas para trabalhar no local, mostram-se como partes interessadas potenciais para uma próxima edição do projeto.

A respeito dos objetivos/estratégia do stakeholder ao participar do projeto, os entrevistados relataram (Quadro 6).

Quadro 6 - Objetivos/estratégia de cada parte interessada ao participar do Proje to

\begin{tabular}{|c|c|}
\hline Entrevistado & Objetivos/estratégia da parte interessada \\
\hline 1 & $\begin{array}{r}\text { Informar aos graduandos sobre a empresa e sobre as vagas de estágio disponíveis e busca receber em } \\
\text { troca do Projeto o maior número de currículos dos es tudantes presentes no evento }\end{array}$ \\
\hline 2 & Uma oportunidade de estar no meio universitário e poder selecionar es tagiários para a empresa \\
\hline 3 & Recrutamento de estagiários e divulgação da empresa \\
\hline 4 & Divulgação da agência entre os alunos e a captação de empreendedores \\
\hline 5 & Captação de candidatos na região sul do país para o nosso banco de dados \\
\hline 6 & Coletar melhores universitários para exercerem funções na nos sa empresa \\
\hline 7 & Apoiar uma atividade que complementa o conhecimento dos alunos e o s coloca em evidência \\
\hline 8 & $\begin{array}{c}\text { Dar satisfação à entidade e equipe organizadora, mas às empres as expositoras também, e com is so } \\
\text { aumentar e melhorar nos sa imagem com atuais e pos síveis clientes }\end{array}$ \\
\hline 9 & Divulgação da marca e fortalecer a entidade apoiadora \\
\hline 10 & Aproximar os estudantes do mundo empresarial e assim impactar na sociedade \\
\hline
\end{tabular}




\begin{tabular}{|c|c|}
\hline 11 & $\begin{array}{c}\text { Desenvolver a equipe, obter lucro, proporcionar aos estudantes e empres as um evento diferenciado } \\
\text { onde todos agreguem valor para si próprios }\end{array}$ \\
\hline 12 & Atender à comunidade universitária exclusivamente \\
\hline 13 & Fornecer à comunidade universitária a oportunidade do espaço físico \\
\hline
\end{tabular}

Fonte: dados da pesquisa.

Nota-se, no quadro 6, semelhanças entre os respondentes 1 a 6 ao citarem a divulgação de seu nome no Projeto, a inclusão no meio universitário e a captação de candidatos. Similaridades também são vistas entre as respostas dos entrevistados 7, 12 e 13 - que têm como foco o apoio, atendimento à comunidade universitária e incentivo à atividades acadêmicas. Já o entrevistado 8 apresentou objetivos ligados à parte de mercado e à reputação de sua imagem com atuais e possíveis clientes.

O quadro 7 apresenta informações sobre a missão do stakeholder e seu impacto. Foram colocados além do número de identificação a categoria da entidade para facilitar o entendimento, com números de identificação aleatórios quanto às questões anteriores.

\begin{tabular}{|c|c|}
\hline $\begin{array}{l}\text { Número de } \\
\text { Identificação }\end{array}$ & Missão da entidade respondente e impacto do Projeto nela \\
\hline $\begin{array}{l}1 \text { - Empresa } \\
\text { Expositora }\end{array}$ & $\begin{array}{c}\text { "Oferecer ao mercado produtos com segurança e design inovador de modo responsável com a } \\
\text { sociedade e o meio ambiente". O projeto nos ajuda a captar jovens que temessa mesma visão e nos } \\
\text { ajudam a realizar noss a mis são }\end{array}$ \\
\hline $\begin{array}{l}2-\text { Empresa } \\
\text { Expositora }\end{array}$ & $\begin{array}{l}\text { Acredito que tenhamos alcançado nosso objetivo, ser conhecido pelos universitários que serão os } \\
\text { futuros profis sionais na área. O recrutamento de estagiário, a divulgação do negócio da empresa e } \\
\text { contatos com clientes potenciais impactam diretamente nos negócios da empresa }\end{array}$ \\
\hline $\begin{array}{l}3-\text { Empresa } \\
\text { Expositora }\end{array}$ & $\begin{array}{l}\text { Melhorar a vida das pessoas através do desenvolvimento de tecnologias aplicadas à agricultura. } \\
\text { Impacta indiretamente, pois para alcançar nossa missão precisamos de pessoas qualificadas }\end{array}$ \\
\hline $\begin{array}{l}4-\text { Empresa } \\
\text { Expositora }\end{array}$ & $\begin{array}{c}\text { A missão é "Transformar Conhecimento em Inovação". O projeto pode auxiliar na divulgação dos } \\
\text { trabalhos da entidade aos alunos de graduação }\end{array}$ \\
\hline $\begin{array}{l}5-\text { Empresa } \\
\text { Expositora }\end{array}$ & $\begin{array}{l}\text { Ser a ferramenta para que as empresas encontrem e selecionem as pes soas certas é a missão da } \\
\text { entidade. E estar nas feiras de carreira para encontrar as pessoas certas para a nossa base. A } \\
\text { participação nesse projeto é essencial para conquistar uma base boa. }\end{array}$ \\
\hline $\begin{array}{l}6-\text { Empresa } \\
\text { Expositora }\end{array}$ & $\begin{array}{l}\text { "Criar vínculos fortes e duradouros com os consumidores e clientes, fornecendo-lhes as melhores } \\
\text { marcas, produtos e serviços". Para que is so seja concluído é necessário que existam profis sionais } \\
\text { capazes de exercer sua função com vontade de levar esse objetivo a diante. }\end{array}$ \\
\hline $\begin{array}{c}7- \\
\text { Universidade }\end{array}$ & $\begin{array}{l}\text { A missão é dar apoio acadêmico e pedagógico ao curso e o projeto fortalece a função da entidade } \\
\text { projetando a imagem do curso }\end{array}$ \\
\hline $\begin{array}{c}8-\text { Apoio } \\
\text { (Infraestrutura) }\end{array}$ & $\begin{array}{c}\text { Não tem missão/o foco é abranger cada vez mais clientes e esse projeto gera um boca a boca que a } \\
\text { entidade acaba alcançando. }\end{array}$ \\
\hline $\begin{array}{c}9-\text { Apoio } \\
\text { (Institucional) }\end{array}$ & Não tem missão e não sabe co \\
\hline $\begin{array}{l}10-\text { Entidade } \\
\text { Organizadora }\end{array}$ & $\begin{array}{c}\text { "Desenvolver seus membros para realizar serviços de qualidade". Um projeto (evento) de tamanha } \\
\text { magnitude, capacita os membros do projeto para organizar eventos e negociar com vários } \\
\text { stakeholders. }\end{array}$ \\
\hline $\begin{array}{l}11 \text { - Entidade } \\
\text { Organizadora }\end{array}$ & $\begin{array}{l}\text { Desenvolver seus membros para realizarem serviços de qualidade. O projeto impacta diretamente na } \\
\text { missão da entidade, comtodo o desenvolvimento que o evento proporciona para os membro s e na } \\
\text { qualidade do resultado final proporcionado por todo esse empenho. }\end{array}$ \\
\hline $\begin{array}{c}12- \\
\text { Universidade }\end{array}$ & Não tem missão/o objetivo é atender à comunidade interna da Universidade \\
\hline $\begin{array}{c}13- \\
\text { - }\end{array}$ & \\
\hline
\end{tabular}

Fonte: dados da pesquisa. 
Percebeu-se que o entrevistado 4, que é uma expositora, não tinha intenção de recrutamento, ao contrário das demais expositoras. As respostas de 1 a 6 apresentaram o mesmo impacto independente da missão de cada uma, associando os candidatos e currículos recebidos, devido ao fato do objetivo principal de participação ser o recrutamento de candidatos.

Quadro 8 - Exigências e aspectos essenciais para participar do Proje to na visão dos stakeholders

\begin{tabular}{|c|c|}
\hline Stakeholder & Exigências e aspectos essenciais para participar do Projeto na visão dos stakeholders \\
\hline 1 & Organização e resultado. \\
\hline 2 & Não há. \\
\hline 3 & fraestrutura adequada, divulgação do evento, grande fluxo de u \\
\hline 4 & Número de participantes \\
\hline 5 & Que seja em um bom local e universidade, que hajame façam valer as contrapartidas \\
\hline 6 & Fator decisório é o financeiro \\
\hline 7 & 0 atividade de ensino, relação de parceria \\
\hline 8 & $\begin{array}{c}\text { Contrato adequado e atualizado, cuidado commateriais da nossa en tidade, cobrança de reposição em } \\
\text { caso de danos }\end{array}$ \\
\hline 9 & Divulgação \\
\hline 10 & Não há pois é a entidade organizadora \\
\hline 11 & Possuir recursos humanos para realizar o Projeto e os investimentos financeiros iniciais \\
\hline 12 & $\begin{array}{c}\text { Disponibilidade dos nossos materiais para empréstimo, liberação das entidades adequadas vinculadas à } \\
\text { Universidade }\end{array}$ \\
\hline 13 & $\begin{array}{l}\text { Ter vinculação acadêmica, ter parte burocrática e liberação certa, que seja marcada com grande } \\
\text { antecedência de preferência e se possível em horários ociosos da nossa atividade principal. }\end{array}$ \\
\hline
\end{tabular}

Fonte: dados da pesquisa.

Quanto às exigências e aspectos para participação no Projeto (Quadro 8), nota-se principalmente que os respondentes associados à Universidade demonstraram exigências ligadas à processos burocráticos, como possuir vínculo com a atividade de ensino e evidenciar a relação de parceria dentro da Universidade. Os benefícios e vantagens observados na participação do projeto são demonstrados no Quadro 9.

Quadro 9 - Benefícios e vantagens do Proje to para a entidade respondente

\begin{tabular}{|c|c|}
\hline Stakeholder & Benefícios e vantagens do Projeto para a entidade respondente \\
\hline 1 & Maior contato com universitários, divulgação da empresa, currículos de qualidade disponíveis \\
\hline 2 & Participação e contato no meio universitário \\
\hline 3 & Exposição da nossa marca, recrutamento de estagiários e prospecção de clientes \\
\hline 4 & Exposição entre os alunos \\
\hline 5 & Bons candidatos para o nosso banco de dados \\
\hline 6 & Visibilidade para a empresa e arrecadação de currículos \\
\hline 7 & $\begin{array}{c}\text { Curso em evidência, imagem institucional, relação de parceria entre a entidade organizadora e o curso } \\
\text { de graduação }\end{array}$ \\
\hline 8 & Divulgação da nossa marca, parte financeira, boca a boca gerado a partir do dia do projeto \\
\hline 9 & Divulgação \\
\hline 10 & Capacitação dos membros, contato com grandes empresas da região \\
\hline 11 & Desenvolvimento da equipe, divulgação da marca perante os stakeholders e lucro \\
\hline 12 & Não há pois é um processo burocrático da entidade respondente \\
\hline 13 & 0 ao aluno, serviço à comunidade; na prática há mais despesas do \\
\hline
\end{tabular}

Fonte: dados da pesquisa. 
Observou-que que as vantagens esperadas pela participação foi compatível com as observações do grupo de discussão. Por exemplo, que as empresas expositoras têm forte participação, chamam a atenção, as empresas tem fama e foram procuradas; estes fatos foram condizentes às observações dos entrevistados 1, 2, 3, 4 e 6 do quadro 9. Outras semelhanças foram observadas quanto à divulgação da marca e nome da entidade organizadora, contato com grandes empresas do mercado de trabalho, desenvolvimento da equipe e lucro. O tópico seguinte abordou a opinião geral sobre o projeto. A intenção era que as respostas adotassem um ponto de vista organizacional, mas notou-se que as respostas partiram de uma perspectiva individual (Quadro 10).

Quadro 10 - Opinião sobre o proje to

\begin{tabular}{|c|c|}
\hline Stakeholder & Opinião sobre o projeto \\
\hline 1 & $\begin{array}{c}\text { É uma ótima iniciativa, traz benefícios tanto para divulgar as empres as como para o conhecimento dos } \\
\text { estudantes participantes }\end{array}$ \\
\hline 2 & $\begin{array}{l}\text { Iniciativa muito boa, não há outra igual na cidade. A equipe organizadora era muito preocupada no dia } \\
\text { com as empresas expositoras, sempre pensando no bem es tar e segurança de cada }\end{array}$ \\
\hline 3 & Não há. \\
\hline 4 & Foi bem organizado, a estrutura para os participantes foi bem adequado \\
\hline 5 & $\begin{array}{c}\text { É de extrema importância para os candidatos saberem das oportunidades e acompanharem as } \\
\text { tendências }\end{array}$ \\
\hline 6 & É um meio facilitador de arrecadação dos futuros profissionais do mercado \\
\hline 7 & É es sencial \\
\hline 8 & Foi ótima, equipe muito organizada, o controle era visível. \\
\hline 9 & Não há. \\
\hline 10 & $\begin{array}{c}\text { É muito importante para dar algo em troca para os universitários e também pelo contato com as } \\
\text { empresas }\end{array}$ \\
\hline 11 & $\begin{array}{c}\text { Traz benefícios para todas as partes envolvidas, a oportunidade que ela proporciona é única por ser a } \\
\text { única da região. }\end{array}$ \\
\hline 12 & Não há opinião pois não conhece o projeto. \\
\hline 13 & É importante pois mostra a presença da Universidade e o apoio que ela dá \\
\hline
\end{tabular}

Fonte: dados da pesquisa.

A última pergunta aos entrevistados pedia sugestões de melhorias para um próximo projeto. O Quadro 11 demonstra estas possibilidades.

\begin{tabular}{|c|c|}
\hline Stakeholder & Sugestões de melhoria \\
\hline 1 & Arrumar as goteiras caso seja no mesmo local da universidade \\
\hline 2 & Contratar segurança para maior tranquilidade da equipe \\
\hline 3 & Divulgação para aumentar mais alunos e empresários \\
\hline 4 & A forma de distribuição dos currículos poderia ser por solução tecnológica \\
\hline 5 & Contrapartidas precisam ser melhor pensadas e realizadas, como divulgação nas mídias \\
\hline 6 & Divulgação \\
\hline 7 & Maior número de empresas \\
\hline 8 & Mais stands e empresas e a divulgação do aluguel de móveis antecipada \\
\hline 9 & Aumento de divulgação dentro da universidade, criar ações diferenciadas de marketing. \\
\hline 10 & Organização e preparo dos staffs \\
\hline 11 & Ampliar as atividades do projeto, como ter palestras, workshops e cursos durante o evento \\
\hline 12 & Não há \\
\hline 13 & A antecedência que foi marcada pode continuar a mesma. \\
\hline
\end{tabular}

Fonte: dados da pesquisa. 
Uma análise das expectativas quanto à melhoria do projeto (Quadro 11) e o suporte ofertado por cada parte interessada (Quadro 5) revela oportunidades de melhor alinhamento entre stakeholders visando uma maior satisfação dos mesmos. Entre os pontos que poderiam ser melhorados estão: suporte para segurança do evento, manutenção/conserto de problemas de infraestrutura (goteiras) e melhoria da divulgação do evento.

A disposição de vários stakeholders em oferecer estes suportes (Quadro 5) revela o potencial de empregar os mesmos recursos de forma diferente, potencializando o atendimento das necessidades de algumas partes interessadas que criticaram o fator divulgação, por exemplo. Para isso, um processo de diagnóstico das necessidades e expectativas (Moura, 2013) bem como uma definição clara do potencial de suporte de cada parte e a determinação de estratégias (Heldman, 2009) precisa ser negociada e determinada no início do projeto.

\section{CONCLUSÃO}

Acerca das modelos para identificação e gerenciamento de partes interessadas trazidos de outros autores, identificou-se uma dificuldade em utilizar um modelo único para coletar todas as informações relevantes para a pesquisa. Este modelo utilizando cinco autores anteriores é uma sugestão a ser replicado por outros projetos e organizações com estrutura organizacional projetizada ou com o modelo de escritório de projetos, tais como ramos de consultoria, pesquisa, engenharias, arquitetura, softwares, entre outros. Sugere-se também uma aplicação no início e outra ao final, com cada stakeholder, a fim de comparar expectativas e satisfação com o projeto e aumentar o sucesso do mesmo sob perspectivas de múltiplos stakeholders.

Considerando o ambiente de dinamicidade e alta tecnologia das organizações, o fato da equipe organizadora não ter realizado o levantamento de partes interessadas no início desta edição do projeto pode ser considerado um risco e retrocesso. As expectativas dos próprios membros no início e final do projeto também não foram comparadas. Pode-se concluir com isto que a empresa júnior, ainda que apresente estrutura organizacional projetizada, ainda precisa amadurecer processos quanto ao gerenciamento dos stakeholders. A insatisfação de alguns em específico poderia levar o projeto ao encerramento ou ao fracasso do mesmo, como no caso da entidade organizadora, universidade e empresas expositoras.

O grupo de discussão foi um método combinado ao estudo de caso fundamental para levantar as unidades de análise e realização de triangulação de dados após a realização das entrevistas. Na segunda parte da pesquisa, realizada com os membros da equipe de forma individual, percebeu-se diferença no volume e profundidade das informações fornecidas. A comunicação da equipe e interação de atividades carece de melhorias e futuras pesquisas sobre seu gerenciamento. Não apenas comunicação interna, mas também externa, visto o suporte que alguns stakeholders poderiam fornecer e que eram exigências de participação de outras partes.

Identificou-se que quase todos os stakeholders que foram incluídos nesta pesquisa têm objetivos e estratégias diferentes; o projeto analisado promoveu a interação e buscou atender as diferentes expectativas de todos. Os objetivos e expectativas de cada parte foram coletados e verificou-se que foram parcialmente atendidos - como os currículos de candidatos às vagas, a divulgação da entidade e o atendimento da universidade ao público.

Em geral, destaca-se a importância das relações formais e informais entre as partes interessadas, que podem ser potencializadas para benefício e percepção de sucesso para cada 
um. Considerando a necessidade de gestão de conhecimento, continuidade e visando o sucesso do projeto, este levantamento e gerenciamento necessita ser feito de forma periódica, formal e por responsáveis que tenham conhecimento e visão geral sobre o tema.

As limitações se deram devido à literatura existente que dizia 'o que' fazer para levantar e gerenciar; e não 'como' realizar. Por isso foi preciso adaptar as obras de diferentes fontes para a criação da ferramenta utilizada. Nesse sentido, o presente estudo de caso, ao apresentar o processo de análise de stakeholders, contribui ao exemplificar a aplicação em um contexto particularmente ainda pouco explorado, que é o contexto dos projetos públicos (Clemente, Marx e Carvalho, 2017) em particular quando possui interfaces com a iniciativa privada.

Foram levantadas três principais vertentes para futuras pesquisas. A primeira, devido às diferenças notadas entre o grupo de discussão e as entrevistas individuais, é discutir a comunicação da equipe dentro do projeto, identificando como ocorre, o que impacta e fatores críticos de sucesso; a segunda é analisar a forma com que os stakeholders identificam e gerenciam os riscos dos projetos podendo-se focar no impacto e interações entre os riscos levantados e possíveis respostas aos riscos. A terceira é realizar uma pesquisa quantitativa para discutir as relações entre partes interessadas, interações direta e indiretas entre elas e o grau de influência e impacto sobre o projeto.

\section{REFERÊNCIAS}

ALVES-FILHO, Antonio. Pessoas na organização: fatores de produção ou fonte de poder estratégico? Departamento de Ciências da Administração - CAD, 2001.

DINSMORE, P. C. \& CAVALIERI, A. Como se tornar um profissional em ge renciamento de projetos. 2. ed. Rio de Janeiro: Qualitymark Editora Ltda., 2005.

BETHLEM, Agrícola, Estratégia empresarial. 2. ed. São Paulo: Atlas, 1997.

CABANIS-BREWIN, J.; DINSMORE, P. C. AMA - Manual de Gerenciamento de Proje tos . 1. ed. Rio de Janeiro: BRASPORT, 2009.

CAMPBELL, A. Stakeholders: the case in favour. Long range planning. London, v. 30, n.3, p. 446-449, june, 1997.

CNEJ. Disponível em: http://www.brasiljunior.org.br/arquivos. Acesso em 07 abr 2014.

CHAVES, E. C. J.; OIKAWA, R.; GALEGALE, N. V.; AZEVEDO, M. M. Avaliação da gestão de stakeholders em implantações de proje tos de sistemas em serviços. In VIII Workshop de Pós-Graduação e pesquisa do Centro Paula Souza. 9 e 10 out 2013, São Paulo-SP.

CHURCHILL, Jr., Gilbert A.; PETER, J. Paul.; Marketing: criando valor para o cliente. 2. Ed. São Paulo: Saraiva, 2000. 
CLELAND, D. I.; IRELAND, L. R. Gerenciamento de projetos. 1 ed. Rio de Janeiro: LTC, 2007.

CLEMENTE, D. H., MARX, R., \& De CARVALHO, M. M. (2017). Gestão de projetos no setor público: uma análise bibliométrica (1988-2014). Revista GEPROS, 12(2), 1.

FACHIN, O. Fundamentos de metodologia. 3. ed. São Paulo: Saraiva, 2001.

VALLE, A. B., SOARES, P. C. A., FINOCCHIO J. JR., \& SILVA L, S. F.. Fundamentos do gerenciamento de projetos. 2. ed. Rio de Janeiro: FGV, 2010.

FREEMAN, R. Edward. Strategic Management: a stakeholder approach. Boston: Pitman, 1984.

Gerenciamento de projetos guia do profissional: volume 1: abordagem geral e definição de escopo/[coordenador Marcus Possi]. Rio de Janeiro: Brasport, 2006.

FRYER, Karen J.; ANTONY, Jiju; DOUGLAS, Alex. Critical success factors of continuous improvement in the public sector: a literature review and some key findings. The TQM

Magazine, v. 19, n. 5, p. 497-517, 2007.

GLESSLER, L.A. Introdução à pesquisa: projetos e relatórios. 2. ed. São Paulo: Loyola, 2004.

HELDMAN, K. Gerência de projetos. 5. ed. Rio de Janeiro: Campus, 2009.

MAXIMIANO, A. C. A. Administração de projetos: como transformar ideias em resultados. 1. ed. São Paulo: Atlas, 1997.

MOURA, H. PMP Sem segredos. 1. ed. São Paulo: Campus, 2013.

PATTON, Q. M. Utilization Focused Evaluation. Sage. 1998.

PROJECT MANAGEMENT INSTITUTE. Um Guia do Conhecimento em Gerenciamento de Projetos: Guia PMBOK. 4. ed. [S.I.]: PMI, 2008.

PROJECT MANAGEMENT INSTITUTE. Um Guia do Conhecimento em Ge renciamento de Projetos: Guia PMBOK. 6. ed. [S.I.]: PMI, 2017.

VARGAS, V. R. Gerenciamento de Projetos: estabelecendo diferenciais competitivos/Ricardo Viana Vargas: prefácio de Reeve Harold R. 6. Ed. Atual. Rio de Janeiro: Brasport, 2005.

YOUNG, T. L. Manual de gerenciamento de projetos: um guia completo de políticas e procedimentos práticos. 1. ed. São Paulo: Clio, 2008. 